\title{
Economic Outcomes for Harvesters under the West Coast Groundfish Trawl Catch Share Program: Have Goals and Objectives Been Met?
}

\section{Melissa N. Errend, Lisa Pfeiffer, Erin Steiner, Marie Guldin \& Amanda Warlick}

To cite this article: Melissa N. Errend, Lisa Pfeiffer, Erin Steiner, Marie Guldin \& Amanda Warlick (2019): Economic Outcomes for Harvesters under the West Coast Groundfish Trawl Catch Share Program: Have Goals and Objectives Been Met?, Coastal Management, DOI: 10.1080/08920753.2018.1522489

To link to this article: https://doi.org/10.1080/08920753.2018.1522489

\section{曲 Published online: 02 Jan 2019.}

\section{Submit your article to this journal $๘$}

Џ Article views: 86

View Crossmark data ¿

Citing articles: 2 View citing articles ¿ 


\title{
Economic Outcomes for Harvesters under the West Coast Groundfish Trawl Catch Share Program: Have Goals and Objectives Been Met?
}

\author{
Melissa N. Errend ${ }^{\mathrm{a} *}$, Lisa Pfeiffer ${ }^{\mathrm{b}}$, Erin Steiner ${ }^{\mathrm{b}}$, Marie Guldin ${ }^{\mathrm{b}}$, and \\ Amanda Warlick ${ }^{a}$ \\ ${ }^{a} E C S$ Federal, LLC under contract to Northwest Fisheries Science Center, National Marine Fisheries \\ Service, National Oceanic and Atmospheric Administration, Seattle, Washington, USA; ${ }^{\mathrm{b}}$ Fisheries \\ Resource Analysis and Monitoring, Northwest Fisheries Science Center, National Marine Fisheries \\ Service, National Oceanic and Atmospheric Administration, Seattle, Washington, USA
}

\begin{abstract}
The West Coast Groundfish Trawl Catch Share Program was designed to achieve multiple economic goals and objectives, including increasing net benefits, profitability, flexibility, and utilization of harvest allocations. In this article, we leverage seven years of comprehensive cost and earnings data to evaluate progress towards these goals with a focus on harvesters. Our assessment shows that five years post-implementation, net benefits to the nation have doubled, and indicators of productivity and profitability have increased. The fleet that targets Pacific whiting has seen the largest gains, due in part to increases in total allowable catch and the elimination of the race-to-fish. However, increased revenues have not been realized to the degree that was expected for harvesters targeting non-whiting groundfish, partly due to lower than predicted consolidation and relatively low quota utilization. Economic outcomes indicate that tradeoffs exist between certain objectives of the program, specifically between achieving full utilization and flexibility for harvesters. Results are discussed in the context of the design and evaluation of catch share programs for diverse, multispecies fisheries.
\end{abstract}

\section{KEYWORDS}

Catch shares; Fisheries; Net benefits; Economic objectives; Profitability; Productivity

\section{Introduction}

Catch shares, where fishermen are given exclusive harvest privileges to a portion of the total allowable catch, are increasingly used to improve economic outcomes in fisheries. By 2013, as many as 200 catch share programs had been implemented globally for the management of over 900 species (Bonzon et al. 2013). Grounded in the recognition that a failure to limit access to common pool resources can lead to the dissipation of economic rents and depletion of fish stocks (Gordon 1954), catch shares have been used to

CONTACT Melissa N. Errend Melissa.errend@noaa.gov E ECS Federal, LLC under contract to Northwest Fisheries Science Center, National Marine Fisheries Service, National Oceanic and Atmospheric Administration, 2725 Montlake Blvd E., Seattle, WA 98112, USA

*Present address: Integrated Statistics, under contract to Northeast Fisheries Science Center, National Marine Fisheries Service, National Oceanic and Atmospheric Administration, Falmouth, MA 02540, USA.

Color versions of one or more of the figures in the article can be found online at www.tandfonline.com/ucmg. 
reduce overcapacity and overfishing, as well as improve socioeconomic outcomes (Costello, Gaines, and Lynham 2008; Grimm et al. 2012; Morrison 2017a). Approaches to designing catch share programs are diverse; harvest privileges may be provided to individuals (individual fishing quotas), be transferable (individual transferable quotas), allocated to groups (e.g., cooperatives), or designated to specific areas (e.g., territorial use rights fisheries).

The design and implementation of catch share programs are important determinants of outcomes (Anderson and Holliday 2007). In particular, catch share programs have been criticized for generating excess consolidation and negatively affecting communities dependent on small-scale commercial fishing (Ecotrust 2009; PEW 2009; U.S. House Comm. on Nat. Res. 2010). In addition, multispecies fisheries may face different obstacles than single-species fisheries, including balancing catch with quota when catch composition is uncertain (Kuriyama et al. 2016; Sanchirico et al. 2006; Squires et al. 1998). To help address potential consequences, U.S. fishery managers have worked to improve and standardize the design and evaluation of catch share programs, including the development of a national catch share policy (Morrison 2017a). In 2009, the National Marine Fisheries Service (NMFS) worked to identify national catch share economic performance indicators (Brinson and Thunberg 2013), and in 2017, produced final guidance for how catch share programs are to be evaluated (Morrison 2017b) as required by the Magnuson-Stevens Fishery Conservation and Management Act (MSA, 16 U.S.C. 1853a). Implemented in 2011, the West Coast Groundfish Trawl Catch Share Program is one of the first programs developed under the national catch share policy and evaluated in accordance with the national guidance.

The West Coast Groundfish Trawl Fishery has a complex past leading up to the implementation of catch shares (Warlick, Steiner, and Guldin 2018). Created in 1982, the Fishery Management Plan covers over 90 species of rockfish, flatfish, and roundfish. Management has sought to resolve two persistent problems: high amounts of discards and overcapacity. Even as the Fishery Management Plan was coming into being, the fishery was facing declining harvests as a result of what now is recognized as overfishing (PFMC 2016b). In 1992, a license-limitation program (limited entry) was implemented to address overcapacity and monthly and bi-monthly landing limits became standard to control effort. Despite this shift in management, between 1999 and 2002, nine species of groundfish were declared overfished. In 2003, a federal buyback program further reduced the size of the fleet; however, in 2009 as the Pacific Fishery Management Council (Council) deliberated catch share management, the fishery was still considered overcapitalized (PFMC and NMFS 2010). Amendment 20 to the management plan created the catch share program that covers the four sectors of the fishery: catcher-processors, motherships, catcher-vessels (both shoreside and at-sea), and shorebased processors. This consists of cooperatives for the catcher-processors and at-sea motherships (including at-sea catcher vessels), and individual quotas for the shoreside catcher vessel fleet. Catcher-processors, motherships, and at-sea catcher vessels primarily target Pacific whiting (whiting), whereas shoreside vessels may target whiting or other, "non-whiting" groundfish species.

Previous studies on the economic outcomes of catch share fisheries have focused on season lengths and the race to fish (Hsueh 2017; Birkenbach, Kaczan, and Smith 2017), 
overcapitalization (Lian, Singh, and Weninger 2009; Solís et al. 2014), regional economic impacts (Leonard and Steiner 2017), sources of rent generation (Reimer, Abbott, and Wilen 2014; Wilen and Richardson 2008), markets and prices (Dewees 1998; Dupont et al. 2005; Herrmann 2000; Scheld and Anderson 2014), the functioning of quota markets (Holland et al. 2015), employment (Abbott, Garber-Yonts, and Wilen 2010), income diversification (Anderson et al. 2017; Kasperski and Holland 2013), defining indicators and metrics (Brinson and Thunberg 2013; Clay, Kitts, and Pinto da Silva 2014), productivity (Solís, Agar, and del Corral 2015; Thunberg, Walden, et al. 2015), and safety (Pfeiffer and Gratz 2016). As noted by Brinson and Thunberg (2016), many studies have compared outcomes to those expected by economic theory, however, few have evaluated program performance specifically in relation to stated goals and objectives.

Here, we leverage seven years of census cost and earnings data to compare changes in economic performance in relation to the goals and expectations. A unique component of the program was mandatory data collection to support program evaluation, including economic data from all catch share participants and full at-sea and dockside monitoring of catches. Our evaluation serves as an important case study of the effectiveness of catch share programs in meeting stated objectives and the importance of collecting economic data for fisheries management. In particular, increased profitability and net benefits are often an expected outcome of rationalization but it is not currently possible to evaluate changes in profitability in most U.S. catch share programs (Brinson and Thunberg 2016). The availability of firm-level data on costs of operations provides greater insight into economic outcomes than can be gleaned from revenue, effort, and landings data alone, which are commonly the best available indicators of economic outcomes.

This paper begins by summarizing the economic goals and expectations of the catch share program. Then, data sources and indicators of program performance are described. In the results section, we first present evidence for changes in net economic benefits to the nation across all participants in the program including harvesters and processors. The remainder of our assessment focuses on catcher vessels: the harvesting sector that was fundamentally affected by the transition to catch shares. We examine the goals and objectives related to changes in harvester profitability, consolidation, productivity, utilization, and flexibility. Complementary results for shorebased processors as well as social outcomes for coastal communities are discussed elsewhere in this issue.

\section{Program goals \& expectations}

Many aspects of the catch share program's stated goals were economic in nature; specifically, the program sought to:

"Create and implement a capacity rationalization plan that increases net economic benefits, creates individual economic stability, provides for full utilization of the trawl sector allocation, considers environmental impacts, and achieves individual accountability of catch and bycatch." (PFMC and NMFS 2010, 5) 
Table 1. Economic components of the program's goals, objectives, and expectations for the catch share program (PFMC and NMFS 2010). ${ }^{\mathrm{a}}$

\begin{tabular}{|c|c|c|}
\hline Goals & Objectives & Expectations \\
\hline $\begin{array}{l}\text { Increase net economic benefits } \\
\text { Create individual economic stability } \\
\text { Provide for full utilization of the trawl } \\
\text { sector allocation } \\
\text { Achieve individual accountability } \\
\text { of catch and bycatch* }\end{array}$ & $\begin{array}{l}\text { Provide for a viable, profitable, } \\
\text { and efficient groundfish fishery } \\
\text { Increase operational flexibility } \\
\text { Promote economic and employment } \\
\text { benefits through the entire seafood } \\
\text { industry* } \\
\text { Provide quality product for the consum- } \\
\text { er* } \\
\text { Provide a mechanism for total } \\
\text { catch accounting* }\end{array}$ & $\begin{array}{l}\text { Consolidation } \\
\text { Changes in timing, effort location, sea- } \\
\text { son length } \\
\text { Increased utilization } \\
\text { Elimination of whiting derby } \\
\text { Increased individual accountability } \\
\text { - }\end{array}$ \\
\hline
\end{tabular}

*Not directly assessed here as they are the subject of other work in this issue.

${ }^{\text {a }}$ See PFMC and NMFS (2010) for a complete list of goals and objectives.

In addition, managers designed a number of economic objectives to support the program's goals, including: provide for a viable, efficient and profitable fishery; increase flexibility in fishing operations; and promote economic and employment benefits for the entire seafood industry (Table 1). The program was prospectively assessed against these goals and objectives in the Final Environmental Impact Statement (FEIS) using a combination of qualitative and quantitative methods (PFMC and NMFS 2010).

Net benefits, or total benefits less costs from society's perspective (NMFS 2007), were expected to increase with rationalization, largely through the consolidation of the fleet. The catcher vessel fleets were estimated to be overcapitalized by 30-66\% (Lian, Singh, and Weninger 2009; PFMC and NMFS 2010). Rationalization, in theory, results in consolidation as quota moves through sale or leasing from less efficient to more efficient vessels (PFMC and NMFS 2010). Consolidation increases profitability by distributing harvests across a smaller number of vessels and decreasing fleet-wide costs through the retirement of redundant capital. Therefore, consolidation was anticipated to be a mechanism for achieving multiple economic goals and objectives such as increased profitability, efficiency, and net benefits (Table 1). Catch shares may also improve efficiency by allowing for vessels to make technical improvements, such as by varying their inputs and outputs (Thunberg, Agar, et al. 2015).

While higher average vessel profits were anticipated as a result of a reduction in both fixed and variable costs, higher total revenue was also expected due to increased harvests. Specifically, individual allocations provide operational flexibility to harvesters, and were expected to allow harvesters to alter the timing, location, and extent of activities across fisheries to decrease variable costs, maximize profitability, and minimize opportunity costs associated with participating in other fisheries. This flexibility was expected to result in increased harvest of target species by allowing harvesters to better avoid constraining overfished species and managers to set less restrictive precautionary limits through direct control over species limits (PFMC and NMFS 2010). Simulations indicated that depending on the extent of bycatch rate reductions, ex-vessel revenues might be between $\$ 30$ and $\$ 50$ million per year under the catch share program, compared to $\$ 22$ to \$25 million under the status quo management (PFMC and NMFS 2010). Increased net benefits were also predicted for the whiting fleet, but via different mechanisms. The elimination of profit-dissipating derby conditions for vessels targeting 
whiting were expected to increase season lengths and profits, as harvesters would no longer race for whiting or associated bycatch (PFMC and NMFS 2010). ${ }^{1}$

In addition, the program included a provision to allow trawl-permitted harvesters to also use fixed gear such as pots and longlines to prosecute the fishery, termed "gearswitching." Gear-switching was expected to allow harvesters greater control over bycatch, particularly in areas with incidental catch of overfished species, as well as potentially reduce environmental impacts, as fixed gear was thought to have fewer habitat impacts compared to bottom trawling (Chuenpagee et al. 2003).

The economic components of the program's goals and objectives are not necessarily complementary. For example, the goal to increase net economic benefits via consolidation, which necessitates exit of vessels from the fishery, undermines a separate program goal to increase the economic stability of individual vessels. To address these concerns, the Council created provisions to help disperse fishery benefits across individuals and communities, such as implementing accumulation limits on quota ownership and setting aside a portion of the quota to potentially redistribute to adversely affected groups (Nayani and Warlick 2018), with the knowledge that these measures might limit consolidation and economic efficiency (Lian, Singh, and Weninger 2009; PFMC and NMFS 2010). In addition, the Council considered whether the economic benefits from increased harvest and efficiency would be sufficient and occur early enough in the program to help participants cover the increased costs of the program, such as the cost of additional at-sea observer coverage and dockside monitoring.

Full dockside and at-sea monitoring was implemented in order to meet the program's goal of achieving individual accountability of catch and bycatch. The program was structured to move away from a program of trip-based landings, where roughly $20 \%$ of trips and discards were monitored, to one based on total catch. It was recognized that complete monitoring was necessary to ensure that all catch (including discards) were matched against quota holdings (PFMC 2008; PFMC and NMFS 2010). While full coverage was anticipated to come at significant cost, expected benefits associated with increased profitability and incentives for bycatch avoidance (Somers et al. 2018) were expected to be substantial.

\section{Data and methods}

\section{Data}

Mandatory revenue and cost data are collected from all harvesters catching and dealers receiving catch share species by the Economic Data Collection (EDC) Program. ${ }^{2}$ EDC data from 2009-2015 are reported here, where data from 2009 to 2010 represent "precatch share" conditions. Landings and trip-level information is obtained from the Pacific Fisheries Information Network (PacFIN) and the Northwest Fisheries Science Center At-Sea Hake Observer Program. Gross revenue includes all revenue generated from shoreside landings, at-sea deliveries, and production of groundfish species in the catch share program (Guldin et al. 2017; Steiner, Guldin, et al. 2017; Steiner, Warlick, et al. 2017; Warlick et al. 2017). Costs include variable costs such as labor expenses, fuel, cost recovery fees, packing materials, and observers as well as fixed costs such as 
capitalized expenditures and expenses on vessel equipment, fishing gear, processing equipment, maintenance, and repair. ${ }^{3}$ Annual cost and revenue information is disaggregated based on landings and days at sea to examine outcomes specific to an individual's participation in the catch share program as opposed to other fisheries (Steiner, Guldin, et al. 2017). Cost disaggregation allows indicators to be presented by fishing activity (distinct harvesting strategies, such as at-sea or shoreside whiting). Values are adjusted for inflation to 2015 dollars. Data confidentiality rules restrict the display of data if there are fewer than three entities, or if a single entity's response comprises more than $90 \%$ of all relevant responses (see Steiner (2016) for more information).

\section{Evaluating amendment goals and objectives with economic performance metrics}

This article uses a variety of metrics to evaluate economic performance; many are part of the national set of performance indicators developed by NMFS in 2009 (Brinson and Thunberg 2013). Each program goal or objective is evaluated using one or more indicators. However, numerous factors affect these metrics including fluctuating global prices and demand, changing environmental conditions, rebuilding stocks, and management changes in other fisheries. Statistically identifying the causal effects of the catch share program from the other ways in which the trawl fishery has changed is methodologically difficult given the breadth of the analysis and the need for rapid evaluation to support the management process. Much of the analysis presented here was developed during the course of the legally mandated five-year review process (PFMC 2017). An examination of trends is an informative contribution to the continuing debate on the utility of catch shares, particularly as current programs evolve and others are developed. Furthermore, ours is an approach commonly taken in other reviews (Agar et al. 2014; Northern Economics 2014; NPFMC 2008, 2010, 2016). Important contextual information is discussed when warranted.

Many management goals and objectives are assessed separately by fleet, namely, for vessels that target Pacific whiting, and those that do not. It is helpful to differentiate between these fleets because in addition to having different target species and management contexts (e.g., derby conditions for whiting), vessels targeting whiting tend to be larger, fish with midwater trawl gear, are more likely to fish in Alaska, and operate in much higher catch volume than the non-whiting fleet. A vessel is categorized as a "whiting vessel" if it targeted Pacific whiting, defined as taking at least one trip in a year in which $50 \%$ or more of its total revenue is derived from Pacific whiting. A vessel is categorized as a "non-whiting vessel" if it only targeted non-whiting groundfish as part of the catch share program in a given year.

\section{Goal: increase net benefits}

Increasing net economic benefits was a key goal of the catch share program. In general, measurement of net benefits in catch share programs are limited by the availability of cost data (Agar et al. 2014; Northern Economics 2014; NPFMC 2008, 2010, 2016). Here, because of the availability of census cost and revenue data, we are able to calculate net benefits by subtracting costs incurred from fishing and processing in the program from gross revenue. ${ }^{4}$ 


\section{Objective: provide for a viable, profitable, and efficient fishery}

Profitability. Providing for profitable and economically stable participation of harvesters in the fishery relates to several goals and objectives of the program (Table 1). EDC data allow examination of financial outcomes from the perspective of vessels (Steiner, Guldin, et al. 2017). Participating vessels' profitability is measured using variable cost net revenue, an estimate of operating profits that accounts for only variable costs of production, and total cost net revenue, a representation of annual profitability that subtracts both variable costs and fixed costs from gross revenue (Figure 1). Both measures are applied to examine the profitability of each vessel's catch share activities exclusively, as opposed to overall profitability, which would include fishing activities outside the catch share program. We calculate means and medians to represent the performance of a typical vessel or fishing activity and 25th and 75th percentiles show the distribution of outcomes across participants. Changes in profitability were expected to occur through a few mechanisms: first, resulting from the retirement of redundant capital or the exit of the least efficient vessels, and second, from opportunities for increased flexibility and utilization of allocations. These mechanisms were expected to vary by fishery; therefore changes in profitability and other performance metrics under this objective are examined separately for whiting and non-whiting vessels.

In addition, we present mean variable cost net revenue with and without accounting for quota revenue and quota costs. Examining the differences between these two measures can reveal the relative impact that quota costs and revenues have on vessel cash flows. We have a limited ability to explore how quota leasing activity affects vessel profitability because while quota expenses related to vessel operations are collected via the EDC Program, revenues from quota leasing are likely under-represented because quota lease revenue and expenses are not collected from quota share owners that are not involved with an actively participating vessel (Steiner, Guldin, et al. 2017). Therefore, our measures of variable cost net revenue including quota expenses can be thought of as a "lower bound" of true variable cost net revenue. The performance of the quota market is analyzed by Holland (2016).

Consolidation and effort. Consolidation, or the number of vessels exiting the fishery since implementation, is an important driver of changes in profits and net benefits. The number and type of fishing vessels participating in the fishery using historical landings
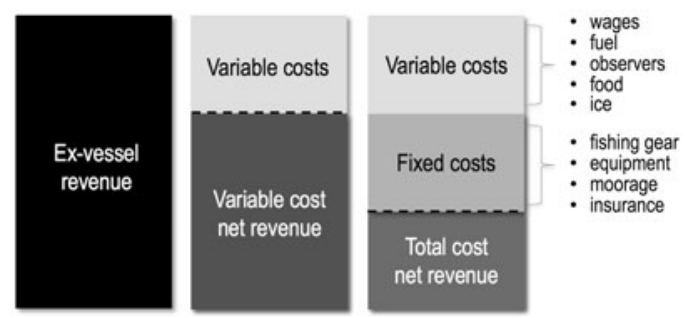

Figure 1. Relationship between revenue, costs and indicators of profitability. Adapted from Steiner et al. (2017). 
information from fish ticket data, which are available for a much longer time period than EDC data, are used to compare the magnitude and rate of consolidation since the 1990s, through the buyback program in 2003, and after the implementation of catch shares in 2011.

To summarize how effort has changed in the fishery, we report the number of active vessels, the average days at sea in the catch share program, average days at sea in noncatch share fisheries, total fleet-wide days at sea, and the average percentage of days at sea spent in the catch share fishery. These metrics provide information about how the fishing season has changed over time, as well as the distribution of effort across catch share and non-catch share fisheries.

Productivity. Productivity, or the relationship between the quantity of fish produced and the amount of inputs used to harvest fish, can be used to understand changes in efficiency and the drivers of changing profitability. Increases in productivity indicate more can be produced with a given level of inputs.

The Lowe Multifactor Productivity index (MFP index) is used to estimate changes in harvesting productivity over time relative to a baseline reference period. The MFP index can be applied in a consistent manner to all catch share programs in the United States, and thus was identified as a metric for evaluation by NMFS (Thunberg, Walden, et al. 2015; Walden et al. 2014). An MFP index greater than 1.0 suggests an increase in productivity over time (through increases in the ratio of outputs to inputs). The MFP index is not intended to assess net returns or profitability, as the output and input indices are constructed using fixed inflation-adjusted prices and they do not include all costs incurred by vessels. Inputs include the value of vessels, capital investments, and labor and fuel expenses. We use the method described by Walden et al. (2014) and EDC capital data to estimate the MFP index for the shoreside whiting and non-whiting catcher vessel fleets.

\section{Goal: provide for full quota utilization}

We calculate the quota utilization rate, or catch to quota ratio, across various target species to evaluate utilization (Equation (1)). Catch includes both harvest $(\mathrm{H})$ and discards (D). The quota, or allocation (A), of each species (i) is the proportion of the annual catch limit provided for the harvesting trawl sectors in a given year $(\mathrm{t})$. If unused allocation from a previous year was carried over as allowed in the regulations, the total weight is added to the sector allocation (carry-over to, CT), if unused allocation was carried over to the following year, it is subtracted (carry over from, CF). Except for sablefish, there was no specific trawl quota prior to the implementation of the program, so hypothetical "allocation" was calculated using the trawl allocation proportion in 2011: the optimum yield in that year was multiplied by the trawl sector allocation in 2011 divided by the 2011 annual catch limit.

$$
U_{i t}=\frac{H_{i t}+D_{i t}}{A_{i t}+C T_{i t}-C F_{i t}}
$$




\section{Objective: increase operational flexibility}

To evaluate changes in operational flexibility, we specifically evaluate two types of adjustment: shifts in the timing of fishing and shifts in gear type. Changes in the timing of fishing are investigated by comparing the mean monthly proportion of annual landings between 2004 and 2010 compared to the 2011 to 2016 period. Changes in gear type, or gear-switching, are investigated by showing the proportion of quota fished with trawl gear versus fixed gear, and the number of vessels using each gear type.

\section{Results and discussion}

\section{Goal: increase net benefits}

Between 2011 and 2015, industry-wide annual net benefits were substantially higher compared to the 2009-2010 average, increasing from \$25 million to \$54 million (Table 2). Several sectors experienced notable increases. Net benefits nearly tripled in the shoreside catcher vessel sector. Shorebased processors saw the greatest increase since implementation of over $\$ 13$ million. However, the at-sea mothership processing sector, on average, saw a slight decrease between the baseline and catch share years. While the catcher-processor sector is the largest contributor to net benefits in any year, net benefits were expected to change the least because the sector was previously rationalized. When catcher-processors are excluded, average annual net benefits increased dramatically from just under $\$ 5$ million to $\$ 26.2$ million.

An important driver of changes in net benefits is changes in the Total Allowable Catch (TAC) for Pacific whiting. In part because of the natural variability of the stock, TAC generally increased from 2011-2015 and was on average 68\% higher than the baseline period (Table 2). These changes in TAC have broad implications for all sectors of the fishery, and confound our ability to attribute changes in net benefits to the change in management, especially in the sectors that target whiting exclusively.

\section{Objective: provide for a viable, profitable, and efficient fishery}

\section{Profitability}

Non-whiting vessels. Despite fleet-wide fishing revenue from non-whiting operations decreasing slightly, from $\$ 30.2$ to $\$ 25.8$ million (PFMC and NMFS 2017), fishing revenue per vessel increased by nearly $\$ 100,000$ from the pre-catch share to the catch share

Table 2. Net benefits by sector (millions of 2015\$). Total Allowable Catch (TAC) for Pacific whiting shown for context.

\begin{tabular}{lcccccccccc}
\hline & 2009 & 2010 & Pre-catch shares avg. & 2011 & 2012 & 2013 & 2014 & 2015 & Catch shares avg. \\
\hline Shoreside catcher vessels & 3.5 & 3.3 & 3.3 & 13.7 & 6.1 & 15.5 & 12.0 & 6.9 & 10.8 \\
Shorebased processors & 0.47 & -4.0 & -1.8 & 17.8 & 17.8 & 16.3 & 10.0 & -0.83 & 12.2 \\
At-sea catcher vessels & 0.41 & 2.9 & 1.7 & 3.1 & 0.30 & 3.0 & 2.4 & 0.23 & 1.8 \\
Motherships & 0.34 & 3.1 & 1.7 & 5.1 & -1.2 & 1.6 & 3.6 & -2.4 & 1.3 \\
Catcher-processors & 10.1 & 30.2 & 20.1 & 21.1 & 16.8 & 29.4 & 49.1 & 22.5 & 27.8 \\
Total & 14.8 & 35.4 & 25.1 & 60.7 & 39.8 & 65.8 & 77.1 & 26.4 & 54.0 \\
\hline $\begin{array}{l}\text { Pacific whiting TAC } \\
\quad \text { (thousands of mt) }\end{array}$ & 136 & 194 & 165 & 291 & 186 & 270 & 316 & 325 & 277 \\
\hline
\end{tabular}


Table 3. Mean individual economic outcomes by fleet. Revenue, variable cost net revenue, and total cost net revenue shown in thousands of 2015 \$. Labor and non-labor variable costs, and fixed costs are shown as a percentage of revenue.

\begin{tabular}{|c|c|c|c|c|c|c|c|c|c|}
\hline & 2009 & 2010 & Pre-catch share avg. & 2011 & 2012 & 2013 & 2014 & 2015 & Catch share avg. \\
\hline \multicolumn{10}{|l|}{ Non-whiting vessels } \\
\hline Revenue & 274 & 262 & 268 & 378 & 331 & 331 & 354 & 399 & 359 \\
\hline Labor variable costs & $41 \%$ & $39 \%$ & $40 \%$ & $37 \%$ & $39 \%$ & $38 \%$ & $38 \%$ & $38 \%$ & $38 \%$ \\
\hline Non-labor variable costs & $22 \%$ & $24 \%$ & $23 \%$ & $20 \%$ & $21 \%$ & $22 \%$ & $19 \%$ & $17 \%$ & $23 \%$ \\
\hline Cost recovery fees & - & - & - & - & - & - & $3 \%$ & $3 \%$ & $3 \%$ \\
\hline Observer costs & $2 \%$ & $1 \%$ & $1 \%$ & $1 \%$ & $2 \%$ & $3 \%$ & $4 \%$ & $5 \%$ & $3 \%$ \\
\hline Fixed costs & $29 \%$ & $27 \%$ & $28 \%$ & $24 \%$ & $29 \%$ & $17 \%$ & $15 \%$ & $15 \%$ & $20 \%$ \\
\hline Variable cost net revenue & 97 & 94 & 95 & 158 & 128 & 125 & 128 & 152 & 138 \\
\hline Total cost net revenue & 17 & 23 & 20 & 66 & 32 & 67 & 77 & 91 & 66 \\
\hline \multicolumn{10}{|l|}{ Whiting vessels } \\
\hline Revenue & 457 & 619 & 538 & 1,277 & 1,207 & 1,428 & 1,340 & 722 & 1,195 \\
\hline Labor variable costs & $32 \%$ & $30 \%$ & $31 \%$ & $30 \%$ & $35 \%$ & $33 \%$ & $35 \%$ & $33 \%$ & $33 \%$ \\
\hline Non-labor variable costs & $24 \%$ & $26 \%$ & $25 \%$ & $20 \%$ & $25 \%$ & $20 \%$ & $23 \%$ & $26 \%$ & $23 \%$ \\
\hline Cost recovery fees & - & - & - & - & - & - & $3 \%$ & $2 \%$ & $3 \%$ \\
\hline Observer costs & $1 \%$ & $1 \%$ & $1 \%$ & $.4 \%$ & $1 \%$ & $1 \%$ & $2 \%$ & $2 \%$ & $1 \%$ \\
\hline Fixed costs & $42 \%$ & $36 \%$ & $39 \%$ & $30 \%$ & $38 \%$ & $23 \%$ & $25 \%$ & $45 \%$ & $32 \%$ \\
\hline Variable cost net revenue & 195 & 259 & 227 & 631 & 478 & 658 & 505 & 260 & 507 \\
\hline Total cost net revenue & 5 & 34 & 20 & 250 & 23 & 329 & 174 & -65 & 142 \\
\hline
\end{tabular}

period (Table 3). Following expectations, average fixed costs and labor costs decreased as a proportion of revenue, likely driven by the exit of some high-cost vessels and remaining vessels' ability to better optimize seasonal harvest. As a result, mean total cost net revenue more than tripled from pre-catch share levels. The distribution of variable cost net revenue has also changed over time (Figure 2). The 75th percentile of variable cost net revenue increased over the catch share period, while it decreased slightly for the 25th percentile of vessels. This indicates that the most profitable vessels have seen the largest increases in profitability compared to the median or lowest quartile.

While total variable costs as a proportion of revenue have not increased, there have been notable shifts in individual cost categories. Expenses as a percentage of revenue for fuel and supplies have decreased, while observer costs increased from less than $1 \%$ in 2011 to 5\% of revenue in 2015 ( $\$ 402$ per day in 2015), following the gradual expiration of a subsidy for observer coverage that was implemented to ease the transition to full observer coverage (PFMC and NMFS 2017). Observer costs and cost recovery fees (MSA-mandated fees to recover the costs directly related to management, data collection, and enforcement (16 U.S.C. 1854(d)(2))) together amounted to $8 \%$ of revenue in 2015.

When including quota costs and revenues, mean variable cost and total cost net revenue are still higher in every post-implementation year compared to baseline years (Figure 3). The percent difference between variable cost net revenue with and without including quota costs and revenues varies by year, from a low in 2012 (mean variable cost net revenue was $0.5 \%$ lower with quota included) to a high in 2015 (mean variable cost net revenue was $25 \%$ lower with quota included).

Whiting vessels. Average annual profitability for whiting vessels increased under catch shares (Table 3). Mean revenue and variable cost net revenue per vessel each experienced at least a two-fold increase, and mean total cost net revenue increased from 


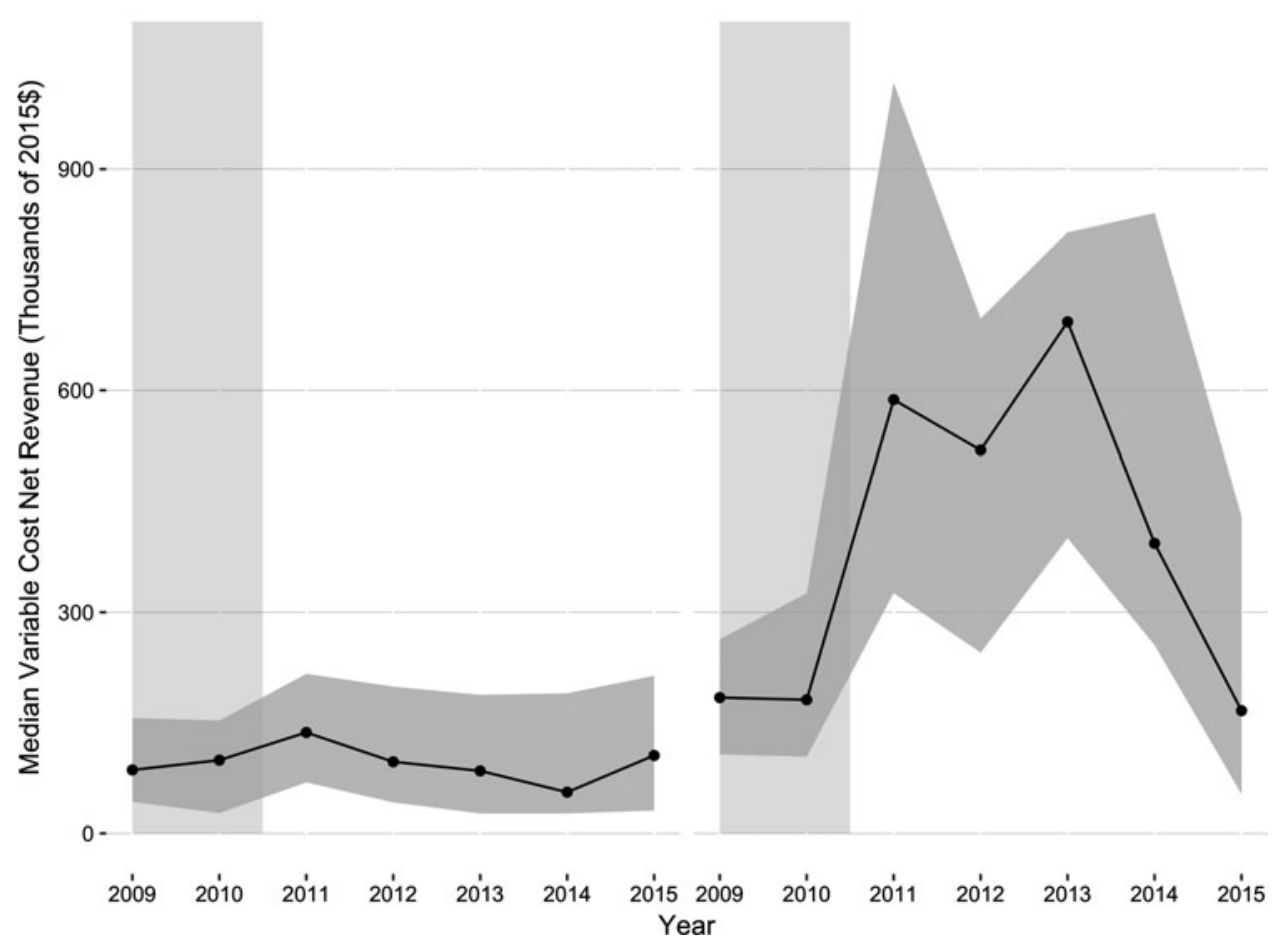

Figure 2. Median annual variable cost net revenue by fleet (thousands of 2015 \$). Interquartile ranges are shown in dark gray. Light gray shaded area indicates the pre-catch share period.

$\$ 20,000$ to over $\$ 140,000$ per vessel. Similar to non-whiting vessels, fixed costs as a percentage of revenue have declined the most, in part due to the retirement of redundant capital. The interquartile range, a measure of distributional outcomes, has increased compared to baseline years. In the first year of the program, median variable cost net revenue for vessels in the 75th percentile was three times higher than for those in the 25th percentile (Figure 2). Observer costs and cost recovery fees increased over the catch share period, causing total non-labor variable costs as a percentage of revenue to increase, while other operating costs decreased as a proportion of revenue.

However, increases in TAC are an important driver of higher average revenue and total cost net revenue after the implementation of the catch share program. Accounting for higher harvest volumes, increases in profitability were more modest. Total cost net revenue per ton generally increased over the catch share period (by $69 \%)$, while variable cost net revenue per ton was roughly the same (1\%, data not shown). Together, this indicates that TAC-driven increases in revenue, flexibility to use inputs more efficiently, and capacity-reducing consolidation were all drivers of increasing total cost net revenue.

Not all years were profitable for the whiting fleet under catch shares. There was a downturn in profitability in 2015 , shown by negative total cost net revenue and a $50 \%$ reduction in ex-vessel revenue from the previous year, despite comparable TAC. This 


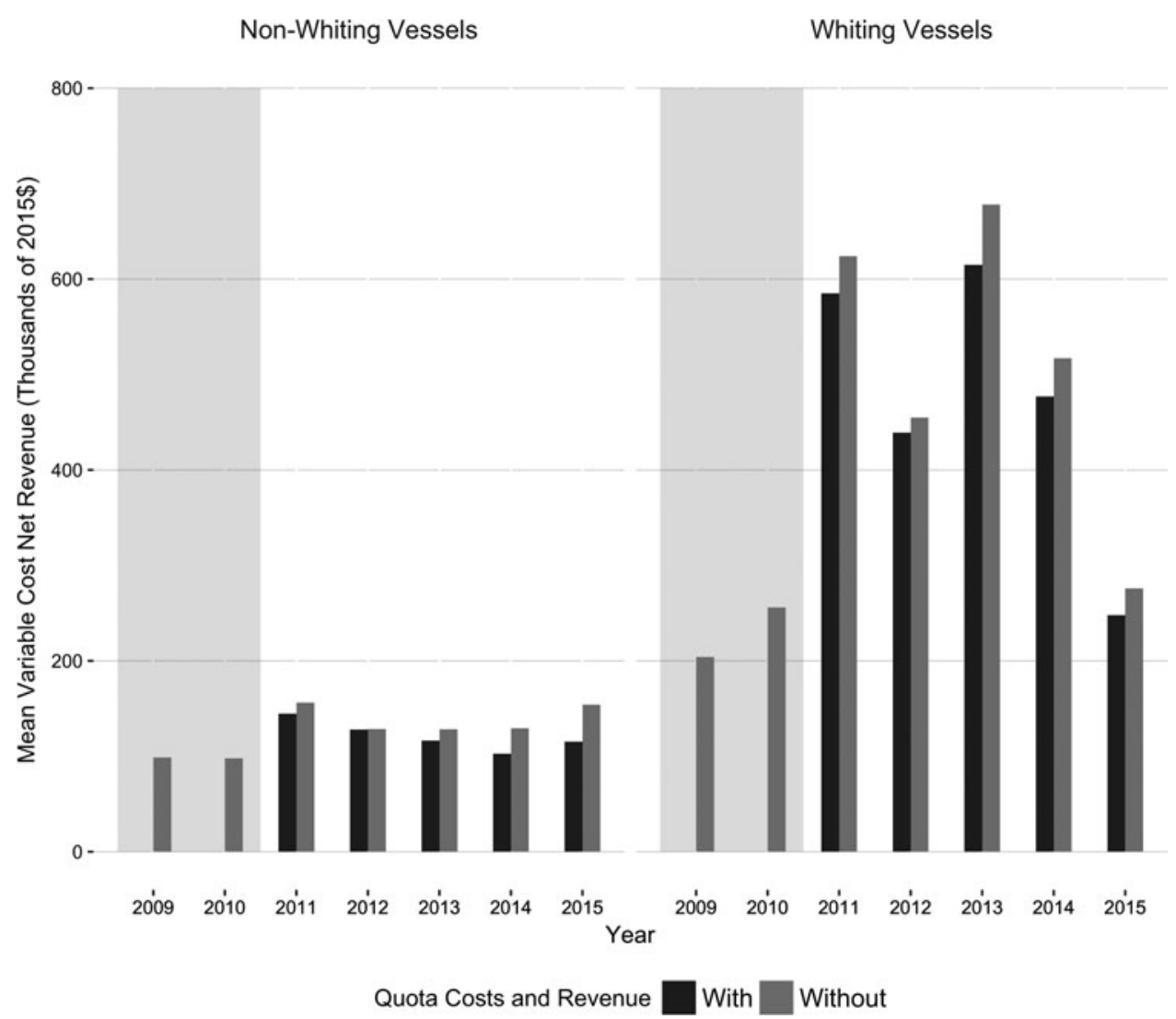

Figure 3. Mean annual variable cost net revenue from participating in the catch share program (thousands of 2015 \$) without (black) and with (gray) quota costs and revenue included in calculation of variable cost net revenue for non-whiting catcher vessels (left) and whiting catcher vessels (right). Light gray shaded area indicates the pre-catch share period.

may be attributed to a widespread oceanographic anomaly in the North Pacific, "the Blob," a marine heatwave that spread throughout 2014 and 2015 and may have had numerous ecosystem effects (Kintisch 2015). In 2015, harvesters reported being unable to locate harvestable concentrations of whiting (PFMC 2016a) and only caught half of the TAC.

Accounting for quota costs and revenue reduces mean variable cost revenue between $4 \%$ and $11 \%$ in any year (Figure 3 ). This range was larger for non-whiting vessels likely because many whiting vessels do not pay directly for leased quota. Whiting processors were allocated $20 \%$ of the whiting quota and generally distribute it to delivering vessels (PFMC and NMFS 2017) and at-sea whiting vessels obtain quota from the mothership cooperative. Quota may still be "paid for" through ex-vessel price adjustments or other mechanisms, but it is not often captured as a direct quota cost. In fact, the increase in quota costs observed is the result of whiting vessels leasing quota for non-whiting species; non-whiting species are caught as bycatch in the whiting fishery but can also be used to target non-whiting groundfish. 


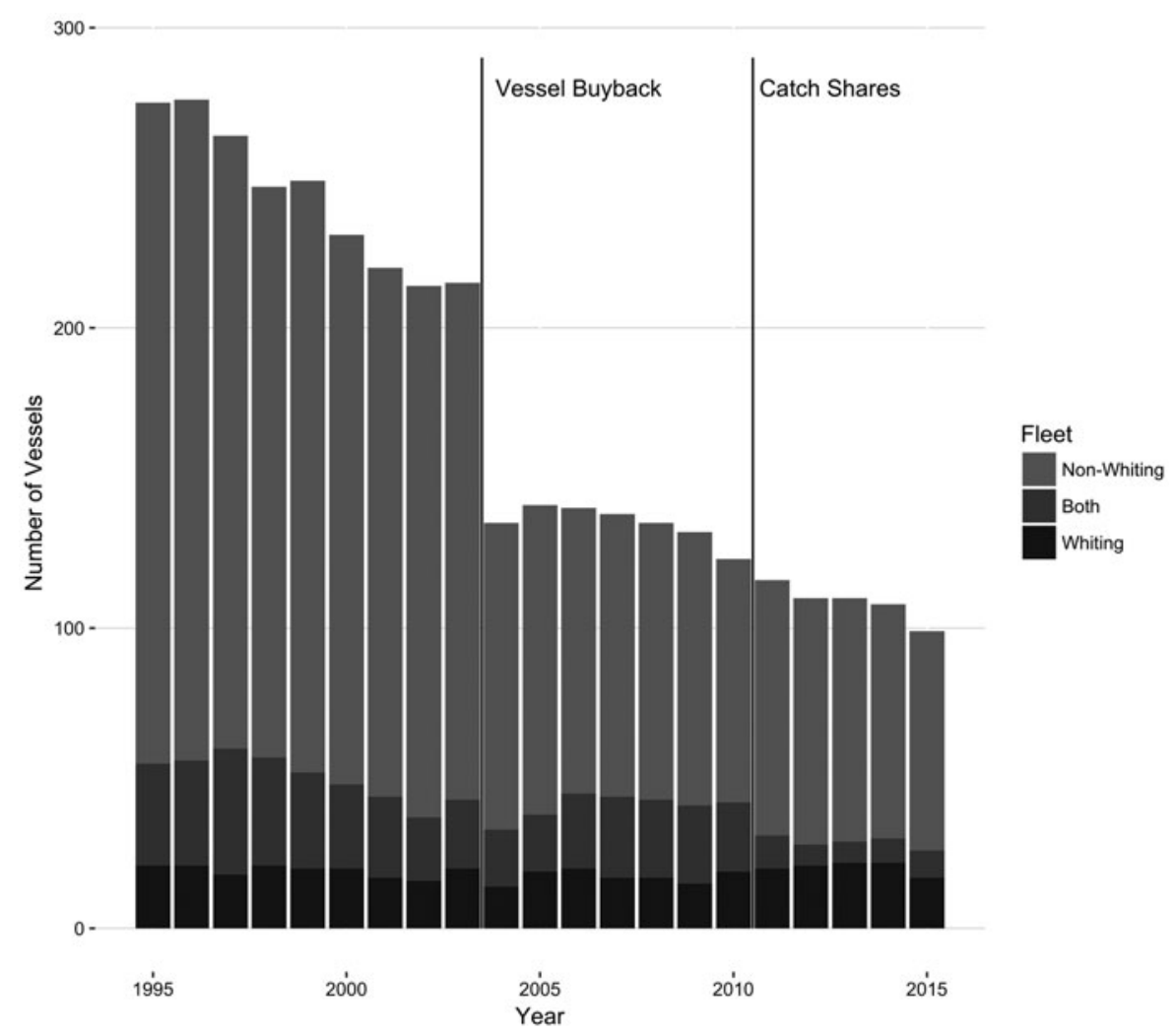

Figure 4. Number of active vessels participating in shoreside and at-sea Pacific whiting (black), nonwhiting groundfish (gray), or in both fleets (dark gray) since 1995. The vessel buyback program (2003) and the implementation of the catch share program (2011) are shown.

\section{Consolidation and effort}

The number of active vessels in the groundfish fishery has been decreasing since the 1990s (Figure 4) (Warlick, Steiner, and Guldin 2018). A federal buyback program in 2003 permanently removed 91 vessels and associated permits from the fishery (Holland, Steiner, and Warlick 2017). However, since catch shares, the number of non-whiting vessels participating remains greater than what was predicted. The FEIS predicted a 50-66\% reduction (PFMC and NMFS 2010), yet in 2015, the number of non-whiting vessels had only decreased by $24 \%$ compared to 2009 . Consolidation of the whiting fleet is more consistent with expectations, which predicted $30-37 \%$ declines and compared to the baseline years, the number of vessels in the whiting fleet declined by $26 \%$ and 37\% in 2014 and 2015, respectively (Table 4). However, low vessel participation in 2015 likely reflects poor fishing conditions. In addition, there was a notable decline in the number of vessels that participate in both the non-whiting and whiting fisheries, a possible indication of increased specialization (Figure 4).

The decline in the number of vessels and the decline in total days at sea in the catch share program indicate that the amount of capital in the fishery has decreased 
Table 4. Number of vessels and effort (days at sea) by fleet. Fleet-wide total days at sea (DAS) include effort in both catch share (CS) and non-catch share fisheries.

\begin{tabular}{|c|c|c|c|c|c|c|c|c|c|c|}
\hline & 2009 & & 2010 & $\begin{array}{l}\text { Pre-catch } \\
\text { share avg. }\end{array}$ & 2011 & 2012 & 2013 & 2014 & 2015 & $\begin{array}{c}\text { Catch } \\
\text { share avg. }\end{array}$ \\
\hline \multirow{6}{*}{$\begin{array}{l}\text { Non-whiting } \\
\text { vessels }\end{array}$} & No. of vessels & 93 & 88 & & 82 & 82 & 80 & 75 & 71 & \\
\hline & Total fleet-wide DAS & 10,254 & 9,057 & 9,656 & 7,961 & 8,357 & 7,819 & 7,950 & 7,328 & 7,883 \\
\hline & Avg. DAS per vessel & 110 & 103 & 106.5 & 97 & 102 & 98 & 106 & 103 & 101 \\
\hline & Avg. CS DAS & 73 & 62 & 67.5 & 50 & 51 & 50 & 48 & 47 & 49 \\
\hline & Avg. non-CS DAS & 55 & 55 & 55 & 61 & 67 & 61 & 75 & 68 & 66 \\
\hline & $\%$ CS DAS & $65 \%$ & $60 \%$ & $63 \%$ & $52 \%$ & $50 \%$ & $51 \%$ & $45 \%$ & $45 \%$ & $49 \%$ \\
\hline \multirow{6}{*}{$\begin{array}{l}\text { Whiting } \\
\text { vessels }\end{array}$} & No. of vessels & 41 & 41 & & 31 & 28 & 29 & 30 & 26 & \\
\hline & Total fleet-wide DAS & 5,693 & 6,434 & 6,064 & 5,376 & 4,356 & 4,896 & 5,137 & 4,169 & 4,787 \\
\hline & Avg. DAS per vessel & 139 & 157 & 148 & 173 & 156 & 169 & 171 & 160 & 166 \\
\hline & Avg. CS DAS & 66 & 75 & 70.5 & 81 & 81 & 82 & 89 & 80 & 83 \\
\hline & Avg. non-CS DAS & 83 & 91 & 87 & 103 & 87 & 101 & 94 & 104 & 98 \\
\hline & $\%$ CS DAS & $48 \%$ & $48 \%$ & $48 \%$ & $46 \%$ & $52 \%$ & $49 \%$ & $52 \%$ & $50 \%$ & $50 \%$ \\
\hline
\end{tabular}

(Table 4). Individually, however, vessels may respond to increased flexibility or take advantage of economies of scale by increasing or decreasing their effort. In the nonwhiting fishery, the elimination of trip-limit management meant that vessels could potentially catch the same amount of fish in fewer days at sea. By contrast, in the whiting fishery, the elimination of the race to fish meant that vessels were likely to lengthen their fishing season and/or spend more days at sea. Vessels might also have spent more or less time in non-catch share fisheries, such as shrimp, Dungeness crab, and Alaskan fisheries.

For non-whiting groundfish vessels, effort in the catch share fishery decreased both in terms of the number of vessels and the average days at sea (Table 4). Because total landings also declined, this decrease may be attributed to both greater catch efficiency and lower landings. As effort decreased in the catch share fishery, the proportion of days spent in other fisheries increased by $15-20 \%$, such that vessels spent less than half of their time fishing in the catch share fishery in 2014 and 2015.

For whiting vessels, following the elimination of derby fishing and coinciding with a decrease in the number of active vessels and an increasing TAC, harvesters spent more time at sea, on average. The average number of days at sea in the catch share fishery has increased by about $17 \%$, but harvesters have consistently spent about half their time fishing in the catch share program.

\section{Productivity}

The MFP index indicates that productivity has increased for the shoreside groundfish fleets, consistent with expectations. For the non-whiting fleet, the MFP index has increased over time, indicating that more outputs (fish production value) are produced with a given amount of inputs (labor, energy, and capital) (Table 5). The MFP index increased from an average of 1 to an average of 1.31 in the catch share period. For the shoreside whiting fleet, annual average output after the implementation of catch shares was $\$ 25.7$ million-almost double the baseline period. This increase was largely due to increases in TAC, and would be even higher were it not for low quota attainment in 2015. The MFP index increased substantially after catch share implementation but 
Table 5. Multifactor Productivity (MFP) indices for shoreside whiting and non-whiting vessels.

\begin{tabular}{llllllllll}
\hline & 2009 & 2010 & Pre-catch share avg. & 2011 & 2012 & 2013 & 2014 & 2015 & Catch share avg. \\
\hline Non-whiting vessels & 0.96 & 1.05 & 1 & 1.24 & 1.25 & 1.29 & 1.33 & 1.43 & 1.31 \\
Shoreside whiting vessels & 1 & 1 & 1 & 1.84 & 1.28 & 1.56 & 1.49 & 1.11 & 1.46 \\
\hline
\end{tabular}

especially in 2011, suggesting that efficiency has increased, as was expected, as a result of both consolidation and additional flexibility.

\section{Goal: provide for full utilization}

Despite predictions for increased attainment, quota utilization for many species remains low (Table 6). On average, utilization of non-whiting quota is less than $20 \%$. In recent years, species have fallen into two groups: species whose annual allocations were nearly fully harvested, like Pacific whiting, petrale sole, and sablefish, and species whose utilization rates are consistently low. Quota utilization of the latter group was expected to increase as rebuilt species became less constraining, allowing greater harvest of cooccurring species. Consistently under-harvested stocks include Dover sole, thornyheads, rockfish, and several other species of flatfish. These decreases in attainment are driven by both steady increases in harvest limits and decreases in landings. In the case of sablefish, Dover sole, and thornyheads, these species are commonly caught by trawl gear as a complex where sablefish constrains the harvest of the other two species; as harvest limits for sablefish have decreased from a high in 2009 and a portion of the sablefish quota has been caught with fixed gear, attainment for Dover sole and thornyheads have also decreased, despite increasing allocations. The decrease in Pacific whiting utilization is driven entirely by low catches in 2015.

\section{Objective: increase operational flexibility}

\section{Timing of landings}

The catch share program allows participants to manage the timing of their portfolio of fishing activities to effectively maximize expected profit and minimize opportunity costs. Differences across whiting and non-whiting fleets may be primarily due to the differences in management prior to the catch share program.

Previously, the non-whiting fleet was managed under bi-monthly trip limits that spread harvest effort throughout the year. This system made it so that although the groundfish season was open all year, in some months the opportunity cost of groundfish participation may have been high if harvesters could have been participating in other fisheries. However, under catch shares, we have not observed major shifts in the timing of aggregate landings (Figure 5). Non-whiting landings continue to be spread throughout the year, although there is a slightly higher proportion landed in March and December, and a slightly lower proportion landed in June and July.

In contrast, the catch share program has led to a lengthening of the fishing season in both the at-sea and shoreside whiting fisheries (Figure 5). Vessels previously competed for the sector-wide allocation of TAC, resulting in a derby fishery within the shoreside and at-sea sectors, where the majority of shoreside landings occurred in June through August. The shoreside fleet harvested at least half of their annual quota within two 
Table 6. Pre-catch share (2009-2010) and catch share (2011-2015) total groundfish catch trawl sector allocation and quota utilization rate by species or group (metric tons). Trawl sector harvest limits for each species were estimated for 2009 and 2010 as optimum yield multiplied by the proportion of the annual catch limit allocated to the trawl sector in 2011.

\begin{tabular}{|c|c|c|c|c|c|c|}
\hline \multirow[b]{2}{*}{ Species or species group } & \multicolumn{2}{|c|}{ Catch (mt) } & \multicolumn{2}{|c|}{ Sector harvest limits (mt) } & \multicolumn{2}{|c|}{ Quota utilization rate } \\
\hline & 2009-2010 & 2011-2015 & 2009-2010 & 2011-2015 & 2009-2010 & 2011-2015 \\
\hline Dover sole & 11,616 & 7,181 & 14,675 & 26,984 & 0.79 & 0.29 \\
\hline Sablefish North & 3,108 & 2,089 & 3,150 & 2,206 & 0.99 & 0.95 \\
\hline Sablefish South & 123 & 227 & 538 & 604 & 0.23 & 0.40 \\
\hline Thornyheads & 3,000 & 1,646 & 3,550 & 3,590 & 0.84 & 0.47 \\
\hline Petrale sole & 1,383 & 1,763 & 2,153 & 1,832 & 0.64 & 0.96 \\
\hline All other flatfish & 5,950 & 3,153 & 24,838 & 21,889 & 0.24 & 0.16 \\
\hline Semi-pelagic rockfish & 178 & 984 & 3693 & 4244 & 0.05 & 0.22 \\
\hline Other rockfish & 1,181 & 737 & 4,527 & 5,096 & 0.26 & 0.15 \\
\hline Pacific whiting* & 81,448 & 128,410 & 84,195 & 160,983 & 0.97 & 0.83 \\
\hline Total non-whiting & 24,740 & 19,582 & 100,449 & 103,226 & 0.24 & 0.19 \\
\hline
\end{tabular}

*Excludes the catcher-processor allocation and landings.
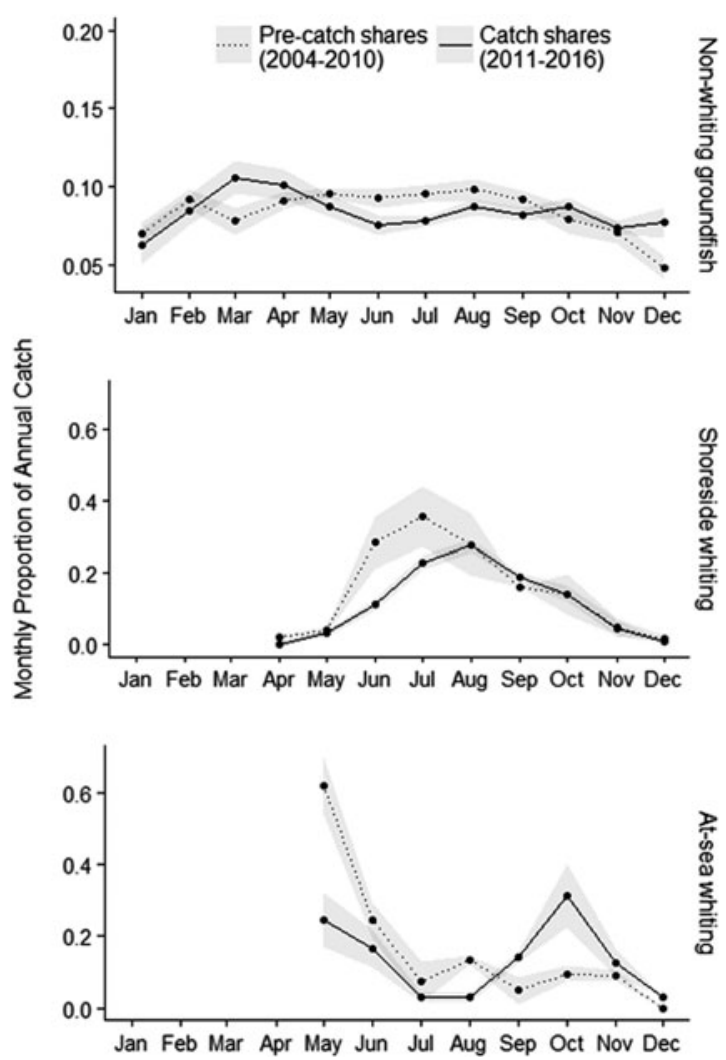

Figure 5. Mean monthly proportion of annual landings by sector in 2004-2010 (dotted lines) and 2011-2016 (solid lines). The shaded areas represent one standard deviation from the mean.

weeks of the start of the season for six out of seven years leading up to catch shares (Steiner, Warlick, et al. 2017). Under catch shares, effort has been more evenly distributed from June through October. An even more notable shift can be seen for the at-sea whiting fleet; after the implementation of catch shares, processing continued into 


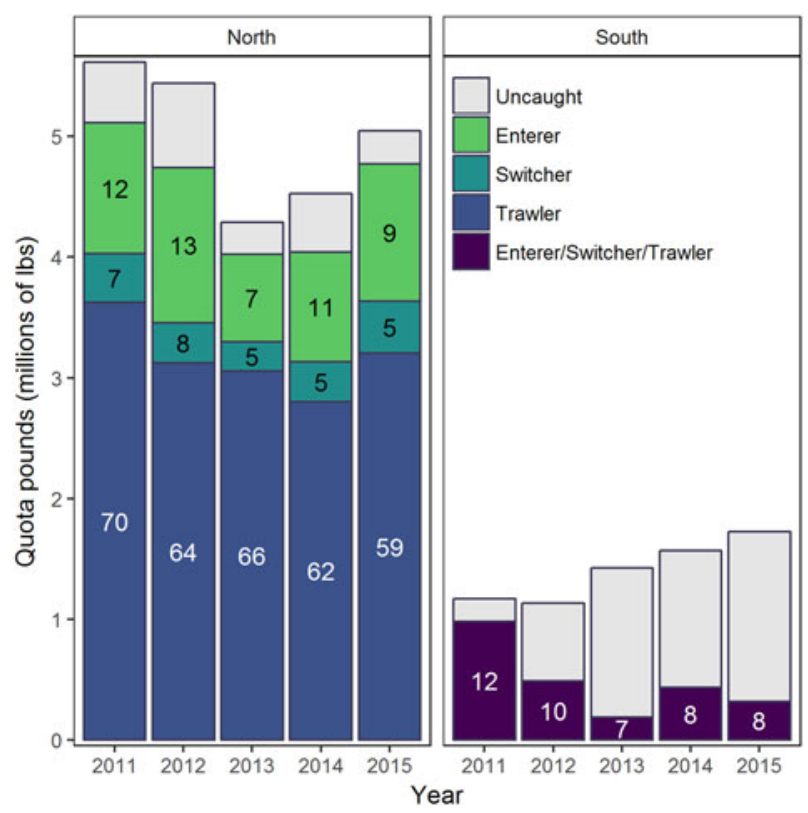

Figure 6. Utilization of northern (left) and southern (right) sablefish quota by vessel category and number of vessels in each vessel category. Sablefish in the West Coast groundfish fishery is managed as two stocks, defined by $36^{\circ} \mathrm{N}$ latitude. To protect confidential data, the landings of southern sablefish quota are not separated by category.

October in all years. These changes in the timing of fishing indicate both an end to the derby fishery in the whiting sectors and more operational flexibility.

\section{Gear type}

The gear-switching provision was intended to allow each vessel to determine its most profitable fishing strategy and to minimize impacts on ocean-bottom habitat (PFMC and NMFS 2010). Sablefish caught with fixed gear is $20-60 \%$ more valuable per pound, on average, than sablefish caught with trawl gear, although sablefish caught with trawl gear are caught as a complex with Dover sole, thornyheads, and other marketable species making overall profit margins similar (PFMC and NMFS 2017).

Gear-switching vessels are classified into two groups based on their previous activities (from 2000 to 2010). "Enterers" are vessels that had not previously fished in the limited entry trawl groundfish fishery but acquired trawl permits. "Switchers" are vessels that previously fished with trawl gear in the limited entry trawl fishery. Enterers outnumbered switchers in each year of the program, but were highest in 2011 and 2012. This may be because of high sablefish prices in 2011 (PFMC and NMFS 2017), and potentially because at the start of the program vessels were trying to determine which activities would be most profitable.

Sablefish in the West Coast groundfish fishery is managed as two stocks, defined by $36^{\circ} \mathrm{N}$ latitude. For northern sablefish quota (left panel of Figure 6), vessels using fixed gear caught an average of $28 \%$ of the quota. In 2015, there were nine enterers and five switchers targeting northern sablefish with fixed gear, and 59 trawlers. 
For southern sablefish quota, nearly all vessels were classified as enterers using fixed gear. Attainment of southern sablefish quota is much lower than northern quota, and has decreased since a high of $84 \%$ in 2011 to $19 \%$ in 2015 (right panel of Figure 6).

The extensive use of fixed gear by new entrants into the fishery was not an anticipated result of the program. While price differences were well recognized, the gearswitching provision was only discussed in the context of trawlers adding it to their portfolio (PFMC and NMFS 2010). Currently, the use of sablefish quota by fixed gear fishermen is being discussed as a contributing factor to the low attainment of thornyheads and Dover sole that are caught with sablefish when using trawl gear. However, it has also allowed entry into the fishery through acquiring relatively small amounts of sablefish quota, especially for the underutilized southern portion of the sablefish quota.

\section{Conclusion}

Over the first five years of catch share management, the West Coast trawl groundfish fishery underwent a number of changes, many of which align with the goals and expectations of the catch share program: net benefits to the nation increased, as did the average profitability and productivity of both whiting and non-whiting harvesting operations. We provide evidence for two key mechanisms through which profitability has increased: consolidation within the whiting and non-whiting sectors, and increased opportunities for flexibility in the amount, timing, and type of effort expended in the catch share fishery. As expected, with the elimination of race-to-fish incentives, whiting harvesters have spread their effort across the season. Higher TAC has also contributed to higher average profits for whiting vessels. The adjustments for non-whiting harvesters have been more complex. The number of days at sea (both fleet-wide and the average per vessel) decreased, suggesting that there was excess capacity and that the trip-limit system may have compelled vessels to take more trips than necessary to catch the available fish. Non-whiting harvesters have increased the number of days and the proportion of days in non-catch share fisheries, suggesting that the increased flexibility may allow them to take advantage of opportunities in other fisheries. The gear-switching provision has also affected participation and flexibility: vessels operating under the gear-switching provision harvested about $28 \%$ of the northern sablefish quota and about $37 \%$ of the southern sablefish quota.

However, several outcomes were not consistent with expectations. First, consolidation in the non-whiting fleet has been less than anticipated. The rationalization process is likely still ongoing and may be affected by several other factors; specifically, quota shares could not be permanently sold until 2014, observer expenses were subsidized through 2015, and a number of pre-catch share regulations that constrain consolidation and efficiency remain in place, including several gear type and area restrictions that could confer even greater operational flexibility if removed or modified. If these factors have limited consolidation, they may have also limited the growth in net benefits and profitability observed in the first five years of the program. 
Second, the program's goal of providing for full quota utilization has not been achieved. For many species of roundfish, flatfish, and rockfish, less than half of the allocation is harvested each year. While for most species the fishery has never come close to full utilization, both increasing catch limits and decreasing total landings are contributing to a decline in utilization. Several factors may contribute to the current and ongoing low catch attainment for many species. Industry participants have suggested that low market demand, as well as competition from Canadian groundfish and tilapia aquaculture limit the value of West Coast groundfish. ${ }^{5}$ In addition, the greater flexibility of harvester operations has potentially had some unintended consequences for processors. Previously, bimonthly landing limits ensured a steady flow of non-whiting groundfish deliveries, while the catch share program allows harvesters to operate more efficiently, which has resulted in fewer days at sea and fewer deliveries to processors, even while the overall temporal distribution of landings has not changed (Guldin et al. 2018). Processors have suggested that this negatively affects their profitability. Finally, even with the greater flexibility of the catch share program, harvesters cannot perfectly match catches to their quota holdings, meaning that some species will invariably be constraining. Full observer coverage and full catch accounting means that harvesters cannot avoid the quota constraint by discarding (Somers et al. 2018). Notably, sablefish has emerged as a constraining species.

In many ways, the outcomes of the West Coast Groundfish Trawl Catch Share Program support a growing body of evidence that catch share programs are effective tools for improving economic conditions, namely by reducing excess capacity, increasing profits for remaining participants, and eliminating derby conditions. However, more subtle, complex, and even competing goals have proved harder to achieve, and are challenging for managers to reconcile.

First, the benefits of individual quotas combined with full accountability come at a cost, particularly in the multispecies non-whiting fishery. Benefits include the ability to effectively enforce catch limits, a disincentive to discard unwanted or constraining catches, and incentives to match catches with quota holdings (Sanchirico et al. 2006; Squires et al. 1998), while costs include additional management and monitoring-related expenses, which amounted to $8 \%$ of revenue in 2015 . While it was expected that catchquota balancing would increase harvests and associated revenues would more than offset the costs of full monitoring, participants predicted these management costs would reduce profitability, discourage investments in capital, or disadvantage smaller vessels whose monitoring costs make up a higher proportion of their revenue (PFMC and NMFS 2010). In the first five years of the program, quota utilization rates remain low for many species. The near-elimination of discarding has resulted in several high-value or low-catch limit species constraining the catches of other species (Somers et al. 2018). The lower-than-predicted utilization and revenue leaves managers with the challenge of answering the industry's call for reduced monitoring costs while honoring the program's goal of full accountability of catch and bycatch.

In addition, the gear-switching provision was intended to provide an additional source of flexibility to trawlers, ultimately to increase utilization. However, in practice, this has been used more by "Enterers" using fixed gear to prosecute the trawl fishery more than trawl vessels switching between gears. The issue has sparked questions about 
the utility of the provision, particularly when increased harvest of sablefish using fixed gear inevitably reduces the utilization of marketable, and underutilized, incidentally caught species such as Dover sole and thornyheads. The Council must now reconcile potential benefits of gear-switching, including reduced environmental impacts, with the goal of full utilization.

Potential tradeoffs and uncertainty associated with the program's more innovative components, such as the role of bycatch avoidance in catch-quota balancing, or gearswitching, likely require additional research and commensurate precaution when considered in the design of multispecies catch share programs. It is worth noting that outcomes are likely due to a complex interaction of factors internal and external to the fishery. Future programs may benefit from both the timely removal of preexisting rules and regulations that may limit program efficacy, as well as advance prioritization of goals and objectives, including an assessment of tradeoffs. Future research may also focus on the relative impact of different program elements, such as accumulation limits and penalties for overages, and external forces, such as market demand, on utilization rates.

\section{Notes}

1. Excluding the catcher-processor sector, which had been managed as a cooperative since 1997.

2. More information available at: https://www.nwfsc.noaa.gov/research/divisions/fram/ economic/economic_data_reports.cfm

3. Costs may be considered an underestimate because EDC forms only capture costs that are directly related to vessel fishing operations, and do not include other business-related expenses such as vehicles or office costs.

4. Buyback fees are not included as costs in the calculation of net economic benefits because they are transfers to taxpayers and, thus, part of the net benefits to the nation that the fishery produces. Buyback fees are included as variable costs in profitability calculations for individual participants.

5. Agenda items F.6.b and F.6.d in the November 2016 Briefing Book: http://www.pcouncil. org/resources/archives/briefing-books/november-2016-briefing-book/

\section{Disclosure statement}

No potential conflict of interest was reported by the authors.

\section{References}

Abbott, J. K., B. Garber-Yonts, and J. E. Wilen. 2010. Employment and remuneration effects of IFQs in the Bering Sea/Aleutian Islands crab fisheries. Marine Resource Economics 25 (4): 333-54.

Agar, J. J., J. A. Stephen, A. Strelcheck, and A. Diagne. 2014. The Gulf of Mexico red snapper IFQ program: The first five years. Marine Resource Economics 29 (2):177-98.

Anderson, L. G., and M. C. Holliday. 2007. The Design and Use of Limited Access Privilege Programs. NOAA Tech. Memo NMFS-F/SPO-86, US Department of Commerce, National Oceanic and Atmospheric Administration, National Marine Fisheries Service, Silver Spring, MD.

Anderson, S. C., E. J. Ward, A. O. Shelton, M. D. Adkison, A. H. Beaudreau, R. E. Brenner, A. C. Haynie, J. C. Shriver, J. T. Watson, and B. C. Williams. 2017. Benefits and risks of 
diversification for individual fishers. Proceedings of the National Academy of Sciences 114 (40): 10797-802.

Birkenbach, A. M., D. J. Kaczan, and M. D. Smith. 2017. Catch shares slow the race to fish. Nature 544 (7649):223-6.

Bonzon, K., K. McIlwain, C. K. Strauss, and T. V. Leuvan. 2013. Catch Share Design Manual, Volume 1: A Guide for Managers and Fishermen. Environmental Defense Fund.

Brinson, A. A., and E. M. Thunberg. 2013. The Economic Performance of US Catch Share Programs. NOAA Tech. Memo NMFS-F/SPO-133. US Department of Commerce, National Oceanic and Atmospheric Administration, National Marine Fisheries Service, Silver Spring, MD.

Brinson, A. A., and E. M. Thunberg. 2016. Performance of federally managed catch share fisheries in the United States. Fisheries Research 179:213-23.

Chuenpagee, R., L. E. Morgan, S. M. Maxwell, E. A. Norse, and D. Pauly. 2003. Shifting gears: Assessing collateral impacts of fishing methods in US waters. Frontiers in Ecology 1 (10): 517-24.

Clay, P. M., A. Kitts, and P. Pinto da Silva. 2014. Measuring the social and economic performance of catch share programs: Definition of metrics and application to the U.S. Northeast region groundfish fishery. Marine Policy 44:27-36.

Costello, C., S. D. Gaines, and J. Lynham. 2008. Can catch shares prevent fisheries collapse? Science 321 (5896):1678-81.

Dewees, C. M. 1998. Effects of individual quota systems on New Zealand and British Columbia fisheries. Ecological Applications 8(1):S133-S8.

Dupont, D. P., K. J. Fox, D. V. Gordon, and R. Q. Grafton. 2005. Profit and price effects of multi-species individual transferable quotas. Journal of Agricultural Economics 56 (1):31-57.

Ecotrust, 2009. A cautionary tale about ITQs in BC fisheries. Briefing Issue 8. Vancouver, Canada: Ecotrust Canada.

Gordon, H. S. 1954. The economic theory of a common-property resource: The fishery. Journal of Political Economy 62 (2):124-42.

Grimm, D., I. Barkhorn, D. Festa, K. Bonzon, J. Boomhower, V. Hovland, and J. Blau. 2012. Assessing catch shares' effects evidence from federal United States and associated British Columbian fisheries. Marine Policy 36(3):644-57.

Guldin, M., E. Steiner, A. Warlick, and J. Leonard. 2017. Economic Data Collection Program First Receiver and Shorebased Processor Report (2009-2015). National Oceanic and Atmospheric Administration, National Marine Fisheries Service, Northwest Fisheries Science Center, Seattle, WA. https://www.nwfsc.noaa.gov/research/divisions/fram/economic/economic_ data_reports.cfm.

Guldin, M., A. Warlick, M. Errend, L. Pfeiffer, and E. Steiner. 2018. Shorebased processor outcomes under catch shares. Coastal Management 46 (6).

Herrmann, M. 2000. Individual vessel quota price-induced effects for Canadian Pacific halibut: Before and after Alaska IFQs. Canadian Journal of Agricultural Economics/Revue Canadienne d'Agroeconomie 48 (2):195-210.

Holland, D. S. 2016. Development of the Pacific groundfish trawl IFQ market. Marine Resource Economics 31 (4):453-64.

Holland, D. S., E. Steiner, and A. Warlick. 2017. Can vessel buybacks pay off: An evaluation of an industry funded fishing vessel buyback. Marine Policy 82:8-15.

Holland, D. S., E. Thunberg, J. Agar, S. Crosson, C. Demarest, S. Kasperski, L. Perruso, E. Steiner, J. Stephen, A. Strelcheck., et al. 2015. US catch share markets: A review of data availability and impediments to transparent markets. Marine Policy 57:103-10.

Hsueh, L. 2017. Quasi-experimental evidence on the 'rights to fish': The effects of catch shares on fishermen's days at sea. Journal of the Association of Environmental and Resource Economists 4 (2):407-45.

Kasperski, S., and D. S. Holland. 2013. Income diversification and risk for fishermen. Proceedings of the National Academy of Sciences of the United States of America 110 (6):2076-2081.

Kintisch, E. 2015. 'The Blob' invades Pacific, flummoxing climate experts. Science 348 (6230): $17-8$. 
Kuriyama, P. T., T. A. Branch, M. A. Bellman, and K. Rutherford. 2016. Catch shares have not led to catch-quota balancing in two North American multispecies trawl fisheries. Marine Policy 71:60-70.

Leonard, J., and E. Steiner. 2017. Initial economic impacts of the U.S. Pacific Coast groundfish fishery individual fishing quota program. North American Journal of Fisheries Management 37 (4):862-81.

Lian, C., R. Singh, and Q. Weninger. 2009. Fleet restructuring, rent generation, and the design of individual fishing quota programs: Empirical evidence from the Pacific Coast groundfish fishery. Marine Resource Economics 24 (4):329-59.

Morrison, W. 2017a. NOAA Catch Share Policy. NMFS Policy Directive 01-121. Department of Commerce, National Oceanic and Atmospheric Adminstration, National Marine Fisheries Service, Silver Spring, MD.

Morrison, W. 2017b. Guidance for Conducting Review of Catch Share Programs. NMFS Procedural Instruction 01-121-01. Department of Commerce, National Oceanic and Atmospheric Administration, National Marine Fisheries Service, Silver Spring, MD.

Nayani, S. E., and A. Warlick. 2018. Implementation challenges for quota set-asides: Policy analysis to inform fisheries management decision-making. Coastal Management 46 (6).

NMFS (National Marine Fisheries Service). 2007. Guidelines for Economic Review of NMFS Regulatory Actions. National Marine Fisheries Procedures for RFA and E.O. 12866 Review Process. Department of Commerce, National Oceanic and Atmospheric Administration, National Marine Fisheries Service, Silver Spring, MD.

Northern Economics, Inc. 2014. Five-year review of the effects of Amendment 80. Prepared for the North Pacific Management Council, Anchorage, AK.

NPFMC (North Pacific Fisheries Management Council). 2008. Gulf of Alaska Rockfish Pilot Program Review. North Pacific Fishery Management Council, Anchorage, AK.

NPFMC. 2010. Five-year Review of the Crab Rationalization Management Program for Bering Sea and Aleutian Islands Crab Fisheries. North Pacific Fishery Management Council, Anchorage, AK.

NPFMC. 2016. Ten-year Program Review for the Crab Rationalization Management Program in the Bering Sea/Aleutian Islands. North Pacific Fishery Management Council, Anchorage, AK.

Pew Charitable Trusts. 2009. Design matters: Making catch shares work. The PEW Environment Group.

Pfeiffer, L., and T. Gratz. 2016. The effect of rights-based fisheries management on risk taking and fishing safety. Proceedings of the National Academy of Sciences 113 (10):2615-20.

PFMC (Pacific Fisheries Management Council). 2008. Appendix A: Analysis of Components, Elements, and Options for the IFQ Alternative. Preliminary Draft Environmental Impact Statement. Pacific Fisheries Management Council, Portland, OR.

PFMC. 2016a. 2017-2018 Groundfish Harvest Specifications and Management Measures Including Changes to Groundfish Stock Designations (Amendment 27 to the Pacific Coast Groundfish Management Plan). Pacific Fisheries Management Council, Portland, OR. http:// www.pcouncil.org/wpcontent/uploads/2016/03/F3_Att1_17-18_GF_SpexCouncilDoc_ APR2016BB.pdf

PFMC. 2016b. Status of the Pacific Coast Groundfish Fishery Stock Assessment and Fishery Evaluation. Pacific Fishery Management Council, Portland, OR. http://www.pcouncil.org/wpcontent/uploads/2017/02/SAFE_Dec2016_02_28_2017.pdf

PFMC. 2017. Follow-on Actions-Issues, Alternatives, and Analysis. Agenda item F.2. Pacific Fishery Management Council, Costa Mesa, CA. http://www.pcouncil.org/wp-content/uploads/ 2017/10/F2_Att6_FollowOnActions_NOV2017BB.pdf

PFMC and NMFS. 2010. Rationalization of the Pacific Coast Groundfish Limited Entry Trawl Fishery; Final Environmental Impact Statement Including Regulatory Impact Review and Initial Regulatory Flexibility Analysis. Pacific Fisheries Management Council and National Marine Fisheries Service, Portland, OR. http://www.pcouncil.org/wp-content/uploads/1_PacificCoast-Grounddfish-Limited-Entry-Trawl-Fishery-FEIS.pdf

PFMC and NMFS. 2017. West Coast Groundfish Trawl Catch Share Program Five Year Review. Pacific Fisheries Management Council and National Marine Fisheries Service, Portland, OR. https://www.pcouncil.org/wp-content/uploads/2018/09/Trawl_CSR_2017_MainDoc_Final.pdf 
Reimer, M. N., J. K. Abbott, and J. E. Wilen. 2014. Unraveling the multiple margins of rent generation from individual transferable quotas. Land Economics 90 (3):538-59.

Sanchirico, J. N., D. S. Holland, K. Quigley, and M. Fina. 2006. Catch-quota balancing in multispecies individual fishing quotas. Marine Policy 30 (6):767-85.

Scheld, A. M., and C. M. Anderson. 2014. Market effects of catch share management: The case of New England multispecies groundfish. ICES Journal of Marine Science 71 (7):1835-45.

Solís, D., J. J. Agar, and J. del Corral. 2015. IFQs and total factor productivity changes: the case of the Gulf of Mexico red snapper fishery. Marine Policy 62 (Supplement C):347-57.

Solís, D., J. D Corral, L. Perruso, and J. J. Agar. 2014. Individual fishing quotas and fishing capacity in the US Gulf of Mexico red snapper fishery. Australian Journal of Agricultural and Resource Economics 58 (2):1-20.

Somers, K., L. Pfeiffer, S. Miller, and W. Morrison. 2018. Using incentives to reduce bycatch and discarding: Results under the West Coast catch share program. Coastal Management 46 (6).

Squires, D., H. Campbell, S. Cunningham, C. Dewees, R. Q. Grafton, S. F. Herrick, J. Kirkley, S. Pascoe, K. Salvanes, B. Shallard, et al. 1998. Individual transferable quotas in multispecies fisheries. Marine Policy 22 (2):135-59.

Steiner, E. 2016. Economic Data Collection Program Administration and Operations Report. National Oceanic and Atmospheric Administration, National Marine Fisheries Service, Northwest Fisheries Science Center, Seattle, WA. https://www.nwfsc.noaa.gov/research/divisions/fram/economic/economic_data_reports.cfm

Steiner, E., M. Guldin, A. Warlick, and L. Pfeiffer. 2017. Economic Data Collection Program Catcher Vessel Report (2009-2015). National Oceanic and Atmospheric Administration, National Marine Fisheries Service, Northwest Fisheries Science Center, Seattle, WA. https:// www.nwfsc.noaa.gov/research/divisions/fram/economic/economic_data_reports.cfm

Steiner, E., A. Warlick, M. Guldin, and L. Pfeiffer. 2017. Economic Data Collection Program Mothership Report (2009-2015). National Oceanic and Atmospheric Administration, National Marine Fisheries Service, Northwest Fisheries Science Center, Seattle, WA. https://www.nwfsc. noaa.gov/research/divisions/fram/economic/economic_data_reports.cfm

Thunberg, E., J. Agar, S. Crosson, B. Garber-Yonts, A. Harley, A. Kitts, T. Lee, C. Lian, C. Liese, M. Pan, et al. 2015. A Snapshot of NOAA Fisheries Data Collection of Commercial Fishery Costs. NOAA Tech. Memo NMFS-F/SPO-154, U.S. Dept. Commerce, National Oceanic and Atmospheric Administration, National Marine Fisheries Service, Silver Spring, MD.

Thunberg, E., J. Walden, J. Agar, R. Felthoven, A. Harley, S. Kasperski, J. Lee, T. Lee, A. Mamula, J. Stephen, et al. 2015. Measuring changes in multi-factor productivity in U.S. catch share fisheries. Marine Policy 62:294-301.

U.S. House Comm. on Nat. Res. 2010. Catch shares as a management option: Criteria for ensuring success-Parts 1 \& 2. U.S. Government Printing Office, Washington, D. C.

Walden, J., J. Agar, R. Felthoven, A. Harley, S. Kasperski, J. Lee, T. Lee, A. Mamula, J. Stephen, A. Strelcheck, et al. 2014. Productivity Change in U.S. Catch Share Fisheries. U.S. Department of Commerce, NOAA Technical Memorandum NMFS-F/SPO (October). https://www.st.nmfs. noaa.gov/economics/fisheries/commercial/catch-share-program/index

Warlick, A., E. Steiner, and M. Guldin. 2018. History of the West Coast groundfish trawl fishery: Tracking socioeconomic characteristics across different management policies in a multispecies fishery. Marine Policy 93:9-21.

Warlick, A., E. Steiner, L. Pfeiffer, and M.Guldin. 2017. Economic Data Collection Program Catcher-Processor Report (2009-2015). National Oceanic and Atmospheric Administration, National Marine Fisheries Service, Northwest Fisheries Science Center, Seattle, WA. https:// www.nwfsc.noaa.gov/research/divisions/fram/economic/economic_data_reports.cfm

Wilen, J. E., and E. J. Richardson. 2008. Rent generation in the Alaskan Pollock conservation cooperative. FAO Fisheries and Aquaculture Technical Paper 504: 361, Rome, Italy. 